\title{
Effect of an Interactive Website to Engage Patients in Advance Care Planning in Outpatient Settings
}

\author{
Michelle Howard, PbD \\ Carole A. Robinson, $\mathrm{PbD}$ \\ Michael McKenzie, MD, FRCPC \\ Gillian Fyles, MD \\ Rebecca L. Sudore, MD \\ Elizabeth Andersen, PbD \\ Neba Arora, MSc \\ Doris Barwich, MD, CCFP \\ Carrie Bernard, MD, FCFP \\ Dawn Elston, MA \\ Rebecca Heyland, BSC \\ Doug Klein, MD, CCFP \\ Erin $\mathrm{McFee}, \mathrm{BScN}$ \\ Lawrence Mroz, PbD \\ Marissa Slaven, MD \\ Amy Tan, MD, CCFP \\ Daren K. Heyland, MD, FRCPC
}

Conflicts of interest: authors report none.

\section{CORRESPONDING AUTHOR}

Michelle Howard, $\mathrm{PhD}$

Department of Family Medicine

McMaster University

David Braley Health Sciences Centre 100 Main St W, 5th Fl

Hamilton, Ontario, Canada L8P 1H6

mhoward@mcmaster.ca

\begin{abstract}
PURPOSE Online programs may help to engage patients in advance care planning in outpatient settings. We sought to implement an online advance care planning program, PREPARE (Prepare for Your Care; http://www. prepareforyourcare.org), at home and evaluate the changes in advance care planning engagement among patients attending outpatient clinics.
\end{abstract}

METHODS We undertook a prospective before-and-after study in 15 primary care clinics and 2 outpatient cancer centers in Canada. Patients were aged 50 years or older (primary care) or 18 years or older (cancer care) and free of cognitive impairment. They used the PREPARE website over 6 weeks, with reminders sent at 2 or 4 weeks. We used the 55 -item Advance Care Planning Engagement Survey, which measures behavior change processes (knowledge, contemplation, self-efficacy, readiness) on 5-point scales and actions relating to substitute decision makers, quality of life, flexibility for the decision maker, and asking doctors questions on an overall scale from 0 to 21; higher scores indicate greater engagement.

RESULTS In total, 315 patients were screened and 172 enrolled, of whom $75 \%$ completed the study (mean age $=65.6$ years, $51 \%$ female, 35\% had cancer). The mean behavior change process score was 2.9 (SD 0.8) at baseline and 3.5 (SD 0.8) at follow-up (mean change $=0.6 ; 95 \% \mathrm{Cl}, 0.49-0.73$ ); the mean action measure score was 4.0 (SD 4.9) at baseline and 5.2 (SD 5.4) at follow-up (mean change $=1.2 ; 95 \% \mathrm{Cl}, 0.54-1.77)$. The effect size was moderate (0.75) for the former and small $(0.23)$ for the latter. Findings were similar in both primary care and cancer care populations.

CONCLUSIONS Implementation of the online PREPARE program in primary care and cancer care clinics increased advance care planning engagement among patients.

Ann Fam Med 2020;18:110-117. https://doi.org/10.1370/afm.2471.

\section{INTRODUCTION}

$\mathrm{D}$ uring serious illness or near the end of life, it is common for patients to be unable to make their own medical decisions. ${ }^{1,2}$ This situation can result in treatments that are incongruent with the patient's values and preferences. ${ }^{3}$ Advance care planning can help ensure that patients' values and preferences are used to direct both in-the-moment and future health care decisions. ${ }^{4,5}$ Advance care planning has been defined as a process that supports adults at any age or stage of health in understanding and sharing their personal values, life goals, and preferences regarding medical care. ${ }^{6}$

The long-term goal of advance care planning is to ensure that "people receive medical care that is consistent with their values, goals and preferences during serious and chronic illness."7 The proximal goals of this planning are to increase patients' and surrogates' understanding of and communication about the patient's values and wishes for future medical care. Interventions that facilitate patients' engagement in advance care planning have been shown to increase the likelihood that clinicians and families incorporate a patient's wishes into treatment decisions, ${ }^{2,8-10}$ reduce hospitalizations and the use of intensive treatments at the end of 
life (according to patients' wishes), and increase use of hospice services. ${ }^{11}$

Health care quality organizations in several jurisdictions recommend that advance care planning be integrated into clinical care. ${ }^{12,13}$ A substantial proportion of patients have thought about their preferences for future health care ${ }^{14-16}$, however, advance care planning conversations do not happen routinely between patients and health care clinicians in primary care or cancer care settings $s^{15-18}$ because of system constraints. ${ }^{19-21}$ Tools that increase engagement in advance care planning in a variety of patient populations and require few resources to implement are of interest. Although there are numerous publicly available tools that could be introduced in clinical settings, $22,23 \mathrm{few}$ have been evaluated for their real-world effectiveness in increasing advance care planning engagement. ${ }^{22}$

The PREPARE (Prepare for Your Care) online program was created to guide people through the key steps of advance care planning, using video stories, with a focus on preparing the patient and substitute decision maker (ie, surrogate) for health care decision making. ${ }^{24}$ This program was developed based on theoretical frameworks of behavior change (http://www. prepareforyourcare.org) and evaluated for efficacy in primary care populations. ${ }^{25,26} \mathrm{In}$ a previous study in low-income senior centers, PREPARE significantly reduced the proportion of people in a precontemplation stage for most advance care planning actions (eg, talking to medical decision maker about wishes, asking doctors questions about desired medical care). ${ }^{24}$ The online tool takes on average 1 hour to review in its entirety. ${ }^{24}$ The PREPARE program, along with an easy-to-read advance directive, increased primary care patients' engagement in advance care planning behaviors in a randomized trial wherein patients used the tool during a study visit with technical support available. ${ }^{25}$ If these tools are to be implemented in realworld settings, further implementation evaluation in broader contexts is needed. We sought to implement PREPARE in primary care and cancer care outpatient settings in real-world practice (ie, outside research visits) to evaluate its impact on the extent of changes in advance care planning engagement among older adults.

\section{METHODS}

\section{Setting and Participant Recruitment}

We conducted this multisite study spanning preimplementation and postimplementation periods in outpatient clinics in Canada. Contacts with interested clinicians led to participation of primary care practices located in the provinces of Ontario (11 practices), Alberta (1 practice), and British Columbia (3 practices), and cancer centers located in British Columbia (2 centers). Eligible patients from primary care practices were aged 50 years or older, and eligible patients from the cancer care settings were aged 18 years or older. Patients had to be able to communicate verbally and read in English, and had to have access to a computer and the Internet at home. Recruitment took place from June 2015 to September 2016.

We obtained ethics approval from the research ethics boards of each participating institution (Hamilton Integrated Research Ethics Board, British Columbia Cancer Agency Research Ethics Board, University of British Columbia Research Ethics Board, and the University of Alberta Health Research Ethics Board).

\section{Screening and Enrollment}

Clinicians either identified eligible patients during a scheduled clinic visit until targets were met, or if preferable, prepared a list of patients with an upcoming visit who met the eligibility criteria, contacted them by telephone, and obtained their consent to speak with a research assistant (RA) about the study. The RA then obtained informed consent to participate from patients. The RA administered baseline questionnaires by telephone or at a clinic visit, including demographic questions relating to age, sex, education, ethnicity, and frailty. ${ }^{27}$ Patients were then given (in person, by mail, or by e-mail) a pamphlet about PREPARE (found on the home page at http://www.prepareforyourcare.org) that includes brief information about the website and instructions on how to access it at home. The RAs did not facilitate use of the online program, and patients were not given any instructions about engaging in other advance care planning activities.

\section{Intervention and Follow-up}

The PREPARE online program uses video stories, modeling of advance care planning behaviors, and a 5 -step process. The tool was designed to motivate and prepare individuals to discuss their values and care preferences with their family, friends, and clinicians. Through tailored algorithms, PREPARE asks individuals about their values and helps them make an action plan. PREPARE then creates a unique, printed "Summary of My Wishes" and has the capacity to save the individual's preferences. ${ }^{24}$

Two weeks postbaseline, an RA called patients to ask if they had reviewed the tool. If they had, there was no further contact until the 6-week follow-up measure. If they had not $(10 \%$ in primary care; this information was not collected in cancer care), the RA called again at 4 weeks to encourage use. The follow-up period of 6 weeks was chosen to allow patients enough time to use the tool and in light of previous studies of 
PREPARE that demonstrated increased advance care planning engagement between 1 week and 3 months based on the validated Advance Care Planning Engagement Survey (described below). ${ }^{25}$ The mean follow-up period was 6.6 weeks.

\section{Outcome Measurement}

Our study outcomes were based on the validated 55-item Advance Care Planning Engagement Survey (https://prepareforyourcare.org/research). ${ }^{28-30}$ This survey is based on stages of behavior change, meaning that questions ask about processes that precede actual actions (including knowledge, contemplation, self-efficacy, readiness) as well as actions, such as discussing one's wishes with the substitute decision maker and completing advance directives. The conceptual framework for advance care planning behaviors includes (1) engaging substitute decision makers, (2) considering acceptable quality of life, (3) considering medical decisions such as the care desired if very sick or near end of life, (4) considering flexibility for decision makers, such as whether surrogates could change prior decisions based on new contexts if in the patient's best interest, and (5) asking doctors questions that would help in medical decision making. ${ }^{28,29}$ Within each domain, questions pertain to behavior change processes on 5-point Likert scales where a score of 1 indicates the lowest level of engagement and 5 indicates the highest. Advance care planning actions were elicited within the readiness questions, which include responses of "I have never thought about it" (precontemplation); "I have thought about it but I am not ready to do it"; (contemplation) "I am planning to do it in the next 6 months" (preparation) "I am definitely planning to do it in the next 30 days" (action); and, "I have already done it" (maintenance). If a patient reported "I have already done it," they were considered to have completed that action for that behavior. The overall action score ranges from 0 to 21, where higher scores indicate greater engagement.

In previous studies of PREPARE, behavior change process scores increased more than action scores over 1 week, ${ }_{,}{ }^{24}$ and the difference on overall survey scores between respondents who had and had not completed an advance directive was 1.0. ${ }^{29}$ These studies suggest that meaningful changes of approximately 1 point across the entire survey can be seen within our 6 -week time frame and correspond to specific advance care planning actions.

\section{Sample Size and Statistical Analysis}

We estimated a sample size of 50 patients in each setting (total 100 patients) would provide $90 \%$ power to detect a difference in engagement scores based on published moderate effect size norms of the survey (one-half of a standard deviation, or 0.5 to 0.7 ). ${ }^{25} \mathrm{We}$ also planned additional analyses in the primary care cohort (not reported here) and continued recruitment in that setting.

Behavior change process and action scores were calculated for each patient at baseline and follow-up. Mean 5-point Likert scores were computed for an overall behavior change process score and for each domain subscale (knowledge, contemplation, self-efficacy, and readiness). For the action score and subscale scores, all of the readiness questions with responses of "I have already done it" were coded as "yes" $=1$ and summed other responses were coded as 0 . We calculated descriptive statistics for demographic characteristics of the sample. To evaluate changes, the mean differences from before to after implementation, $95 \% \mathrm{CI}$ of the mean difference, and Cohen $d$ effect size coefficient were calculated for all subscale scores. The statistical tests of comparison of means were adjusted for age, sex, education, clinical frailty score, and recruitment setting (primary care or cancer care). We tested whether there was an interaction between change in score and recruitment setting. As a secondary analysis, we evaluated changes from before to after in each of the 2 settings separately, again adjusting tests for age, sex, education, and clinical frailty score. We computed effect sizes for the changes in scores (small, 0.20-0.49; moderate, $0.50-0.79$ i large, $\geq 0.80){ }^{31}$

\section{RESULTS}

\section{Patient Enrollment and Characteristics}

In the primary care clinics, 225 patients were approached, $14(6.2 \%)$ could not be reached by the RAs for enrollment, 64 (28.4\%) declined, and 124 (55.1\%) were enrolled. A total of 89 enrolled patients (71.8\%) completed baseline and follow-up measures and were included in analyses. In the cancer centers, 90 patients were approached, and 72 (80.0\%) were enrolled. Two patients were lost to contact before baseline measurement; 70 began the study, and 47 (67.1\%) completed baseline and follow-up measures. Analyses were therefore based on a total of 136 patients from the 2 settings.

The main reasons for declining ( 82 patients total) were lack of interest or time, and not feeling comfortable using computers. The main reasons for not completing the study (45 patients total) were that the patient was no longer interested, became too busy, or, mainly in the cancer setting, became too ill. There were no significant differences on demographic factors between patients who completed vs patients who did not (data not shown). 
The 136 participating patients had a mean age of 65.6 years (SD 11.9), $51.5 \%$ were female, $81.6 \%$ had at least some university education or a college degree, and the majority identified as being of Caucasian/white ethnicity (91.9\%) (Table 1).

\section{Behavior Change Process Scores}

The mean overall behavior change process score was 2.9 (SD 0.8) at baseline and 3.5 (SD 0.8) at follow-up. The mean change was 0.6 (95\% CI, 0.49-0.73), corresponding to a moderate effect size (Cohen $d=0.75$ ) (Table 2).

The effect sizes for the subscales were 0.99 (large) for knowledge, 0.70 (moderate) for contemplation, 0.40 (small) for self-efficacy, and 0.60 (moderate) for readiness.

The mean changes in behavior change process scores were similar for most subscales between the primary care and cancer care settings (Table 3). Only the change in the readiness subscale score differed significantly between settings ( $P=.04$ for interaction), with a greater change in primary care (mean difference $=0.7 ; 95 \% \mathrm{CI}$, $0.50-0.84)$ than in the cancer care setting (mean difference $=0.4$; 95\% CI, 0.18-0.59).

\section{Action Scores}

The mean action score was 4.0 (SD 4.9) at baseline and 5.2 (SD 5.4) at follow-up (mean change $=1.2 ; 95 \% \mathrm{CI}, 0.54-1.77)$ (Table 2). The effect sizes of the overall score $(0.23)$ and the subscale scores were small (all $<0.3$ ).

Increases in the overall action scores were 1.1 (95\% CI, 0.37 to 1.87 ) in primary care and 1.2 (95\% CI, 0.12-2.31) in cancer care (Table 3). The mean changes in most subscale scores were in the same direction and similar in magnitude $(P>.05$ for interaction terms by setting). Only the change in the subscale score for asking doctors questions differed significantly between primary care and cancer care $(P<.001$ for interaction), increasing in the primary care setting (mean difference $=0.1 ; 95 \%$ $\mathrm{CI}, 0.02$ to 0.14$)$ and decreasing in the cancer care setting (mean difference $=-0.2 ; 95 \% \mathrm{CI},-0.32$ to -0.03 ).
Table 1. Demographic and Clinical Characteristics of Study Participants, by Setting and Overall

\begin{tabular}{|c|c|c|c|}
\hline \multirow[b]{2}{*}{ Characteristic } & \multicolumn{2}{|c|}{ Setting } & \multirow[b]{2}{*}{$\begin{array}{c}\text { Total } \\
(\mathrm{N}=136)\end{array}$} \\
\hline & $\begin{array}{l}\text { Primary Care } \\
(\mathrm{n}=89)\end{array}$ & $\begin{array}{c}\text { Cancer Care } \\
(n=47)\end{array}$ & \\
\hline Age, mean (SD), y & $64.9(7.9)$ & $66.8(17.1)$ & $65.6(11.9)$ \\
\hline Sex, female, No. (\%) & $58(65.2)$ & $12(25.5)$ & $70(51.5)$ \\
\hline \multicolumn{4}{|l|}{ Self-rated quality of life, No. (\%) } \\
\hline Excellent & $34(38.2)$ & $5(10.6)$ & $39(28.7)$ \\
\hline Very good & $31(34.8)$ & $19(39.6)$ & $50(36.8)$ \\
\hline Good & $19(21.3)$ & $16(33.3)$ & $35(25.7)$ \\
\hline Fair & $5(5.6)$ & $6(12.5)$ & $11(8.1)$ \\
\hline Poor & $0(0)$ & $1(2.1)$ & $1(0.7)$ \\
\hline \multicolumn{4}{|l|}{ Marital status, No. (\%) } \\
\hline Married/common law & $64(71.9)$ & $36(76.6)$ & $100(73.5)$ \\
\hline Widowed & $9(10.11)$ & $2(4.3)$ & $11(8.1)$ \\
\hline Never married & $7(7.9)$ & $1(2.1)$ & $8(5.9)$ \\
\hline Divorced/separated & $9(10.1)$ & $8(17.0)$ & $17(12.5)$ \\
\hline \multicolumn{4}{|l|}{ Highest level of education, No. (\%) } \\
\hline Some high school or less & $5(5.6)$ & $5(10.6)$ & $10(7.4)$ \\
\hline High school diploma & $9(10.1)$ & $6(12.8)$ & $15(11.0)$ \\
\hline Some university/college degree & $24(27.0)$ & $15(31.9)$ & $39(28.7)$ \\
\hline University degree & $29(32.6)$ & $13(27.7)$ & $42(30.9)$ \\
\hline Graduate degree & $22(24.7)$ & $8(17.0)$ & $30(22.1)$ \\
\hline \multicolumn{4}{|c|}{ Importance of spirituality/religion, No. (\%) } \\
\hline Extremely important & $22(24.7)$ & $7(14.9)$ & $29(21.5)$ \\
\hline Very important & $25(28.1)$ & $9(19.1)$ & $34(25.0)$ \\
\hline Somewhat important & $19(21.3)$ & $10(21.3)$ & $29(21.3)$ \\
\hline Not very important & $12(13.5)$ & $13(27.1)$ & $25(18.4)$ \\
\hline Not at all important & $9(10.1)$ & $8(17.0)$ & $17(13.6)$ \\
\hline Don't know & $1(1.1)$ & $0(0)$ & $1(0.7)$ \\
\hline \multicolumn{4}{|l|}{ Ethnicity, No. (\%) } \\
\hline Asian/Pacific Islander & $0(0)$ & $2(4.3)$ & $2(1.5)$ \\
\hline African/black North American & $1(1.1)$ & $0(0)$ & $1(0.8)$ \\
\hline Caucasian/white & $82(92.1)$ & $43(91.5)$ & $125(91.9)$ \\
\hline East Indian & $1(1.1)$ & $1(2.1)$ & $2(1.5)$ \\
\hline First Nations/Inuit/Metis/Aboriginal & $2(2.2)$ & $0(0)$ & $2(1.5)$ \\
\hline Other & $3(3.4)$ & $1(2.1)$ & $4(3.2)$ \\
\hline \multicolumn{4}{|c|}{ Language spoken on a daily basis, No. (\%) } \\
\hline English & $85(95.5)$ & $47(100.0)$ & $132(97.0)$ \\
\hline French & $0(0)$ & $0(0)$ & $0(0)$ \\
\hline Other & $4(4.5)$ & $0(0)$ & $4(3.0)$ \\
\hline Clinical frailty score, ${ }^{27}$ mean $(S D)^{a}$ & $1.9(0.9)$ & $2.7(1.2)$ & $2.2(1.1)$ \\
\hline \multicolumn{4}{|c|}{$\begin{array}{l}\text { Need help with written instructions/materi- } \\
\text { als, No. (\%) }\end{array}$} \\
\hline Never & $61(68.5)$ & $34(72.3)$ & $95(70.0)$ \\
\hline Rarely & $19(21.3)$ & $7(14.9)$ & $26(19.1)$ \\
\hline Sometimes & $8(9.0)$ & $5(10.6)$ & $13(9.6)$ \\
\hline Often & $1(1.1)$ & $1(2.1)$ & $2(1.5)$ \\
\hline Always & $0(0)$ & $0(0)$ & $0(0)$ \\
\hline
\end{tabular}




\section{DISCUSSION}

In this multisite implementation study among older adults from primary care and outpatient cancer clinics, patients' engagement in advance care plan- ning increased after self-directed use of the online PREPARE program at home. Advance care planning behavior change process scores increased by a mean of 0.6 on a 5 -point scale. A change of this magni-

Table 2. Scores on the Advance Care Planning Engagement Survey at Baseline and Follow-Up in Entire Cohort $(\mathrm{N}=136)$

\begin{tabular}{|c|c|c|c|c|c|}
\hline Measures & $\begin{array}{c}\text { Baseline Score, } \\
\text { Mean (SD) }\end{array}$ & $\begin{array}{c}\text { Follow-up a Score, } \\
\text { Mean (SD) }\end{array}$ & $\begin{array}{c}\text { Mean Difference } \\
(95 \% \mathrm{Cl})\end{array}$ & $\begin{array}{l}\text { Unadjusted } \\
P \text { Value }\end{array}$ & $\begin{array}{l}\text { Adjusted } \\
P \text { Value }\end{array}$ \\
\hline \multicolumn{6}{|l|}{ Behavior change process (all scales $1-5$ ) } \\
\hline Knowledge & $3.2(1.0)$ & $4.1(0.8)$ & $0.9(0.70$ to 1.05$)$ & $<.001$ & $<.001$ \\
\hline Contemplation & $2.4(0.9)$ & $3.2(1.1)$ & $0.8(0.66$ to 0.98$)$ & $<.001$ & $<.001$ \\
\hline Self-efficacy & $3.9(0.8)$ & $4.2(0.7)$ & $0.3(0.11$ to 0.39$)$ & $<.001$ & $<.001$ \\
\hline Readiness & $2.6(1.0)$ & $3.2(1.0)$ & $0.6(0.44$ to 0.71$)$ & $<.001$ & $<.001$ \\
\hline Overall & $2.9(0.8)$ & $3.5(0.8)$ & $0.6(0.49$ to 0.73$)$ & $<.001$ & $<.001$ \\
\hline \multicolumn{6}{|l|}{ Action (overall scale $0-21$ ) } \\
\hline Medical decision makers (5 items) & $1.2(1.3)$ & $1.5(1.3)$ & 0.3 (0.09 to 0.48$)$ & .004 & .004 \\
\hline Health situations ( 5 items) & $1.2(1.6)$ & $1.4(1.6)$ & $0.2(-0.03$ to 0.41$)$ & .08 & .08 \\
\hline Medical decisions (5 items) & $1.1(1.5)$ & $1.3(1.6)$ & $0.3(0.07$ to 0.48$)$ & .01 & .01 \\
\hline Flexibility (5 items) & $1.2(0.7)$ & $1.4(0.8)$ & $0.2(0.10$ to 0.31$)$ & $<.001$ & $<.001$ \\
\hline Asking doctors questions (1 item) & $0.1(0.3)$ & $0.1(0.3)$ & $0.0(-0.07$ to 0.06$)$ & .86 & .86 \\
\hline Overall & $4.0(4.9)$ & $5.2(5.4)$ & $1.2(0.54$ to 1.77$)$ & $<.001$ & $<.001$ \\
\hline
\end{tabular}

Table 3. Scores on the Advance Care Planning Engagement Survey at Baseline and Follow-Up by Setting

\begin{tabular}{|c|c|c|c|c|c|c|c|c|c|}
\hline \multirow[b]{2}{*}{ Measures } & \multicolumn{4}{|c|}{ Primary Care $(n=89)$} & \multicolumn{4}{|c|}{ Cancer Care $(n=47)$} & \multirow[b]{2}{*}{$\begin{array}{l}\text { Inter- } \\
\text { action } P \\
\text { Value }^{c}\end{array}$} \\
\hline & $\begin{array}{l}\text { Baseline } \\
\text { Score, } \\
\text { Mean (SD) }\end{array}$ & $\begin{array}{l}\text { Follow-up }^{a} \\
\text { Score, } \\
\text { Mean (SD) }\end{array}$ & $\begin{array}{c}\text { Mean } \\
\text { Difference } \\
(95 \% \mathrm{Cl})\end{array}$ & $\begin{array}{c}P \\
\text { Value }^{b}\end{array}$ & $\begin{array}{l}\text { Baseline } \\
\text { Score, } \\
\text { Mean (SD) }\end{array}$ & $\begin{array}{l}\text { Follow-up }^{a} \\
\text { Score, } \\
\text { Mean (SD) }\end{array}$ & $\begin{array}{c}\text { Mean } \\
\text { Difference } \\
(95 \% \mathrm{Cl})\end{array}$ & $\begin{array}{c}P \\
\text { Value }^{b}\end{array}$ & \\
\hline \multicolumn{10}{|l|}{$\begin{array}{l}\text { Behavior change } \\
\text { process (all } \\
\text { scales 1-5) }\end{array}$} \\
\hline Knowledge & $3.1(1.0)$ & $4.0(0.8)$ & $\begin{array}{c}1.0(0.76 \text { to } \\
1.21)\end{array}$ & $<.001$ & $3.4(1.1)$ & $4.1(0.8)$ & $\begin{array}{l}0.7(0.40 \\
\text { to } 0.92)\end{array}$ & $<.001$ & .07 \\
\hline Contemplation & $2.4(0.8)$ & $3.3(1.0)$ & $\begin{array}{c}0.9(0.67 \text { to } \\
1.08)\end{array}$ & $<.001$ & $2.5(1.0)$ & $3.2(1.2)$ & $\begin{array}{l}0.7(0.45 \\
\text { to } 0.99)\end{array}$ & $<.001$ & .65 \\
\hline Self-efficacy & $3.9(0.8)$ & $4.3(0.7)$ & $\begin{array}{c}0.3(0.15 \text { to } \\
0.48)\end{array}$ & $<.001$ & $4.0(0.9)$ & $4.1(0.8)$ & $\begin{array}{c}0.1(-0.12 \\
\text { to } 0.36)\end{array}$ & .31 & .33 \\
\hline Readiness & $2.5(0.9)$ & $3.2(0.9)$ & $\begin{array}{l}0.7(0.50 \text { to } \\
0.84)\end{array}$ & $<.001$ & $2.9(1.2)$ & $3.3(1.1)$ & $\begin{array}{l}0.4(0.18 \\
\text { to } 0.59)\end{array}$ & $<.001$ & .04 \\
\hline \multicolumn{10}{|l|}{$\begin{array}{c}\text { Action (overall } \\
\text { scale } 0-21 \text { ) }\end{array}$} \\
\hline $\begin{array}{l}\text { Medical deci- } \\
\text { sion makers }\end{array}$ & $1.2(1.4)$ & $1.4(1.3)$ & $\begin{array}{c}0.2(-0.08 \\
\text { to } 0.39)\end{array}$ & .18 & $1.2(1.3)$ & $1.7(1.4)$ & $\begin{array}{l}0.5(0.19 \\
\text { to } 0.90)\end{array}$ & .004 & .16 \\
\hline $\begin{array}{l}\text { Health } \\
\text { situations }\end{array}$ & $1.0(1.4)$ & $1.3(1.6)$ & $\begin{array}{c}0.3(0.01 \text { to } \\
0.51)\end{array}$ & .04 & $1.6(1.8)$ & $1.6(1.7)$ & $\begin{array}{l}0.1(-0.36 \\
\text { to } 0.49)\end{array}$ & .76 & .18 \\
\hline $\begin{array}{l}\text { Medical } \\
\text { decisions }\end{array}$ & $1.1(1.5)$ & $1.3(1.6)$ & $\begin{array}{l}0.2(-0.04 \\
\text { to } 0.48)\end{array}$ & .09 & $1.0(1.5)$ & $1.4(1.7)$ & $\begin{array}{l}0.4(0.01 \\
\text { to } 0.71)\end{array}$ & .04 & .82 \\
\hline Flexibility & $1.2(0.6)$ & $1.3(0.8)$ & $\begin{array}{l}0.2(0.06 \\
\text { to } 0.32)\end{array}$ & .005 & $1.3(0.7)$ & $1.6(0.9)$ & $\begin{array}{l}0.2(0.06 \\
\text { to } 0.42)\end{array}$ & .009 & .23 \\
\hline $\begin{array}{l}\text { Asking doctors } \\
\text { questions }\end{array}$ & $0.01(0.1)$ & $0.1(0.3)$ & $\begin{array}{c}0.1(0.02 \text { to } \\
0.14)\end{array}$ & .007 & $0.3(0.5)$ & $0.2(0.4)$ & $\begin{array}{c}-0.2(-0.32 \\
\text { to }-0.03)\end{array}$ & .02 & $<.001$ \\
\hline Overall & $3.7(4.6)$ & $4.8(5.2)$ & $\begin{array}{c}1.1(0.37 \text { to } \\
1.87)\end{array}$ & $<.001$ & $4.6(5.4)$ & $5.9(5.8)$ & $\begin{array}{l}1.2(0.12 \\
\text { to } 2.31)\end{array}$ & $<.001$ & .17 \\
\hline
\end{tabular}


tude demonstrates that patients are moving along the behavior change pathway from precontemplation, to contemplation, to preparation, to action. ${ }^{24}$ Although a score change of approximately 1.0 has been associated with prior advance directive completion, ${ }^{29}$ the observed change in scores in our study demonstrates that patients are engaging more in a range of advance care planning behaviors, such as contemplation and discussion of wishes.

Our results showed increases in behavior change processes scores and action scores after using PREPARE similar to those of a previous trial evaluating this online program in research settings. ${ }^{25,32}$ In that trial, participants viewed PREPARE in its entirety in a research office, so it is encouraging that in our study, there were increases in advance care planning engagement when patients used the tool on their own at home. Our study timeline may have been more reflective of how the tool would be used if "prescribed" by a health care professional in an outpatient setting, as participants were given several weeks to interact with the tool in their home rather than in a single encounter with a research assistant. Action scores increased by a mean of 1.2 points out of a possible 21 . This finding is similar to that in the previous trial of PREPARE wherein there were lower effect sizes for actions than processes after 3 months of follow-up. ${ }^{25}$ Commonly cited barriers to initiating advance care planning reported by health care professionals include lack of patient readiness and lack of time in the clinical encounter. ${ }^{20,33}$ To increase actions, the PREPARE online program may need to be combined with other strategies, such as an appointment for follow-up with the clinician and reminders to complete actions.

The PREPARE program was designed to engage people who have not previously engaged in advance care planning or not considered it at all. Advance care planning includes several behaviors that then may alter a patient's interactions with and outcomes of health care in the future. The outcomes measured in this study are intermediate outcomes that reflect preparation for medical decision making. Ultimately, realizing the benefits of advance care planning on the important outcomes of quality of care and health care use will likely require multistakeholder interventions and longer follow-up of interventions.

The $75 \%$ completion rate for our study suggests that patients who are provided an advance care planning tool in their health care setting will engage with the tool, however, to achieve this completion rate, RAs provided a reminder. Further research could assess whether combining the PREPARE tool completion at home with a follow-up clinical encounter with a health care professional could increase completion of advance care planning actions. To increase accessibility and efficiency, the PREPARE program offers varying formats and toolkits that can be used to organize advance care planning group events in the community or group medical visits in clinical settings such as primary care and cancer care, in addition to individual use. ${ }^{34}$

Among patients in the cancer care setting, the score for the action subscale of asking doctors questions declined from before to after use of PREPARE, similar to results of a previous study with this program. ${ }^{32}$ In the cancer care setting, patients may have been more engaged in communication with doctors about their treatment and answered accordingly at baseline. After reviewing PREPARE, they may have learned that they had not asked about making medical decisions specifically, thereby changing their answer at the follow-up measure. It is also possible that during the study time period, no new action was undertaken. Among the primary care patients, at baseline, few patients reported having asked doctors questions, suggesting little engagement in advance care planning with physicians in this setting.

It might be expected that the outcomes of the PREPARE program would be different in the 2 groups of patients in this study-adults aged 65 years on average with good self-reported health visiting family practices, compared with patients undergoing cancer treatment or posttreatment follow-up. On the whole, as noted in a prior study, patients in cancer care settings were willing to use the PREPARE program ${ }^{35}$ and had an increase in advance care planning engagement that was similar in magnitude to that among patients from primary care settings.

This study has several limitations. The study settings and patients were not randomly sampled, which may have introduced bias. Also, our before-and-after evaluation did not have a control group. Social desirability and other biases may have influenced patients' responses toward reporting higher engagement.

Patients who agreed to this study evaluating a webbased advance care planning tool may have been more engaged and computer literate because ability and willingness to access the online program was required for eligibility, and the results may not equally apply to patients who did not agree to use or could not access the Internet. Also, patients predominantly identified as Caucasian/white and had a high self-reported level of education, which may limit the generalizability of our findings; however, PREPARE was developed with and tested among ethnically and sociodemographically diverse older adults who had low computer literacy, ${ }_{1}^{24}$ and has shown benefits in these diverse populations. ${ }^{24-26}$ Another limitation to applying the results in community or clinical settings is that RAs contacted 
patients to encourage use of the tool. Furthermore, although prior work has shown that increases in the Advance Care Planning Engagement Survey scores correspond with increases along the behavior change pathway of advance care planning, ${ }^{25}$ data are currently lacking to correlate the threshold cutoffs that would be associated with downstream end-of-life outcomes.

In conclusion, in this real-world study, the online PREPARE program reviewed at home increased advance care planning engagement among patients from primary care and cancer care outpatient settings. This is the first report of PREPARE effectiveness in real-world settings, and the findings should be replicated in other settings. The results suggest that self-directed tools could support advance care planning initiatives in outpatient health care settings and among the public.

To read or post commentaries in response to this article, see it online at http://www.AnnFamMed.org/content/18/2/110.

Key words: advance care planning; end of life care; decision making; decision support techniques; behavior; prospective studies; patient engagement; primary care; oncology

Author affiliations: Department of Family Medicine, McMaster University, Hamilton, Ontario, Canada (Howard, Arora, Bernard, Elston, Slaven); School of Nursing, Thompson Rivers University, Kamloops, British Columbia, Canada (Robinson, Andersen); Radiation Therapy Program, British Columbia Cancer Agency, Vancouver Cancer Centre, Vancouver, British Columbia, Canada (McKenzie); Division of Palliative Care, Department of Medicine, University of British Columbia, Vancouver, British Columbia, Canada (Fyles, Barwich, Mroz); Division of Geriatrics, Department of Medicine, University of California, San Francisco, California, USA (Sudore); Department of Family and Community Medicine, University of Toronto, Toronto, Ontario, Canada (Bernard); Clinical Evaluation Research Unit, Kingston General Hospital, Kingston, Ontario, Canada (R. Heyland, D. Heyland); Department of Family Medicine, University of Alberta, Edmonton, Alberta, Canada (Klein); Bachelor of Science in Nursing Program, Okanagan College, Kelowna, British Columbia, Canada (McFee); Department of Family Medicine, University of Calgary, Calgary, Alberta, Canada (Tan); Department of Public Health Sciences, Queen's University, Kingston, Ontario, Canada (D. Heyland).

Submitted November 18, 2018; submitted, revised, May 12, 2019; accepted May 24, 2019.

Funding support: This research was supported by research grants from the Ontario Ministry of Health and Long-term Care and the Canadian Frailty Network (formerly Technology Evaluation in the Elderly Network), which is supported by the Government of Canada through the Networks of Centres of Excellence (NCE) program, as well as the British Columbia Cancer Foundation.

Disclaimer: The views expressed in this article are those of the authors and do not reflect an official position of their institutions or the funder.

Previous presentation: Howard M, McKenzie M, Robinson C, et al, Efficacy of the PREPARE website to engage patients in advance care planning in primary care and cancer outpatient care: a prospective study; oral presentation at the International Society of Advance Care Planning \& End of Life Care (ACPEL) Conference; September 8, 2017; Banff, Alberta, Canada.

\section{References}

1. Wenger NS, Oye RK, Bellamy PE, et al; The SUPPORT Investigators. Study to Understand Prognoses and Preferences for Outcomes and Risks of Treatments. Prior capacity of patients lacking decision making ability early in hospitalization: implications for advance directive administration. J Gen Intern Med. 1994;9(10):539-543.

2. Silveira MJ, Kim SYH, Langa KM. Advance directives and outcomes of surrogate decision making before death. N Engl J Med. 2010; 362(13):1211-1218.

3. Heyland DK, Ilan R, Jiang X, You JJ, Dodek P. The prevalence of medical error related to end-of-life communication in Canadian hospitals: results of a multicentre observational study. BMJ Qual Saf. 2016;25(9):671-679.

4. Sudore RL, Fried TR. Redefining the "planning" in advance care planning: preparing for end-of-life decision making. Ann Intern Med. 2010;153(4):256-261.

5. Sinuff T, Dodek P, You JJ, et al. Improving end-of-life communication and decision making: the development of a conceptual framework and quality indicators. J Pain Symptom Manage. 2015;49(6): 1070-1080.

6. Sudore RL, Lum HD, You JJ, et al. Defining advance care planning for adults: a consensus definition from a multidisciplinary Delphi panel. J Pain Symptom Manage. 2017;53(5):821-832.e1.

7. Sudore RL, Heyland DK, Lum HD, et al. Outcomes that define successful advance care planning: a Delphi panel consensus. J Pain Symptom Manage. 2018;55(2):245-255.e8.

8. Hammes BJ, Rooney BL. Death and end-of-life planning in one midwestern community. Arch Intern Med. 1998;158(4):383-390.

9. Detering KM, Hancock AD, Reade MC, Silvester W. The impact of advance care planning on end of life care in elderly patients: randomised controlled trial. BMJ. 2010;340:c1345.

10. Metzger M, Song M-K, Ward S, Chang PP-Y, Hanson LC, Lin F-C. A randomized controlled pilot trial to improve advance care planning for LVAD patients and their surrogates. Heart Lung. 2016;45(3): 186-192.

11. Houben CHM, Spruit MA, Groenen MTJ, Wouters EFM, Janssen DJA. Efficacy of advance care planning: a systematic review and meta-analysis. J Am Med Dir Assoc. 2014;15(7):477-489.

12. Institute of Medicine. Dying in America. Improving the Quality and Honoring Individual Preferences Near the End of Life. Washington, DC: National Academies Press; 2014.

13. Health Quality Ontario. Evidence to improve care. Palliative care: care for adults with a progressive, life-limiting illness. https://www. hqontario.ca/Evidence-to-Improve-Care/Quality-Standards/View-allQuality-Standards/Palliative-Care. Accessed Mar 5, 2019.

14. Teixeira AA, Hanvey L, Tayler C, Barwich D, Baxter S, Heyland DK; Canadian Researchers at End of Life Network (CARENET). What do Canadians think of advanced care planning? Findings from an online opinion poll. BMJ Support Palliat Care. 2015;5(1):40-47.

15. Musa I, Seymour J, Narayanasamy MJ, Wada T, Conroy S. A survey of older peoples' attitudes towards advance care planning. Age Ageing. 2015;44(3):371-376.

16. Howard M, Bernard C, Klein D, et al. Older patient engagement in advance care planning in Canadian primary care practices: results of a multisite survey. Can Fam Physician. 2018;64(5):371-377.

17. Robinson C, Kolesar S, Boyko M, Berkowitz J, Calam B, Collins M. Awareness of do-not-resuscitate orders: what do patients know and want? Can Fam Physician. 2012;58(4):e229-e233.

18. O'Sullivan R, Mailo K, Angeles R, Agarwal G. Advance directives: survey of primary care patients. Can Fam Physician. 2015;61(4):353-356.

19. Johnson S, Butow P, Kerridge I, Tattersall M. Advance care planning for cancer patients: a systematic review of perceptions and experiences of patients, families, and healthcare providers. Psychooncology. 2016;25(4):362-386. 
20. De Vleminck A, Houttekier D, Pardon K, et al. Barriers and facilitators for general practitioners to engage in advance care planning: a systematic review. Scand J Prim Health Care. 2013;31(4):215-226.

21. Howard M, Bernard C, Klein D, et al. Barriers to and enablers of advance care planning with patients in primary care: survey of health care providers. Can Fam Physician. 2018;64(4):e190-e198.

22. Butler M, Ratner E, McCreedy E, Shippee N, Kane RL. Decision aids for advance care planning: an overview of the state of the science. Ann Intern Med. 2014;161(6):408-418.

23. Oczkowski SJ, Chung H-O, Hanvey L, Mbuagbaw L, You JJ. Communication tools for end-of-life decision-making in ambulatory care settings: a systematic review and meta-analysis. PLoS One. 2016; 11(4):e0150671.

24. Sudore RL, Knight SJ, McMahan RD, et al. A novel website to prepare diverse older adults for decision making and advance care planning: a pilot study. J Pain Symptom Manage. 2014;47(4):674-686.

25. Sudore RL, Boscardin J, Feuz MA, McMahan RD, Katen MT, Barnes DE. Effect of the PREPARE website vs an easy-to-read advance directive on advance care planning documentation and engagement among veterans: a randomized clinical trial. JAMA Intern Med. 2017; 177(8):1102-1109.

26. Sudore RL, Schillinger D, Katen MT, et al. Engaging diverse Englishand Spanish-speaking older adults in advance care planning: the PREPARE Randomized Clinical Trial. JAMA Intern Med. 2018;178(12): 1616-1625.

27. Rockwood K, Song X, Macknight C, et al. A global clinical measure of fitness and frailty in elderly people. CMAJ. 2005;173(5):489-495.
28. Sudore RL, Stewart AL, Knight SJ, et al. Development and validation of a questionnaire to detect behavior change in multiple advance care planning behaviors. PLoS One. 2013;8(9):e72465.

29. Sudore RL, Heyland DK, Barnes DE, et al. Measuring advance care planning: optimizing the Advance Care Planning Engagement Survey. J Pain Symptom Manage. 2017;53(4):669-681.e8.

30. Howard M, Bonham AJ, Heyland DK, et al. Measuring engagement in advance care planning: a cross-sectional multicentre feasibility study. BMJ Open. 2016;6(6):e010375.

31. Cohen J. Statistical Power for the Behavioral Sciences. 2nd ed. Hillsdale, New Jersey: Lawrence Erlbaum; 1998.

32. Lum HD, Barnes DE, Katen MT, Shi Y, Boscardin J, Sudore RL. Improving a full range of advance care planning behavior change and action domains: the PREPARE randomized trial. J Pain Symptom Manage. 2018;56(4):575-581.e7.

33. You JJ, Downar J, Fowler RA, et al; Canadian Researchers at the End of Life Network. Barriers to goals of care discussions with seriously ill hospitalized patients and their families: a multicenter survey of clinicians. JAMA Intern Med. 2015;175(4):549-556.

34. Lum HD, Jones J, Matlock DD, et al. Advance care planning meets group medical visits: the feasibility of promoting conversations. Ann Fam Med. 2016;14(2):125-132.

35. Cresswell MA, Robinson CA, Fyles G, Bottorff JL, Sudore R. Evaluation of an advance care planning web-based resource: applicability for cancer treatment patients. Support Care Cancer. 2018;26(3): 853-860.

\section{Wt1) 15 \\ Prevent Bias in Patient Care \\ Open your eyes to patients' unique needs with The EveryONE Project's free training toolkit.}

\section{aafp.org/everyone-toolkit}

